\title{
Functional effects of eggs, naturally enriched with conjugated linoleic acid, on the blood lipid profile, development of atherosclerosis and composition of atherosclerotic plaque in apolipoprotein $\mathbf{E}$ and low-density lipoprotein receptor double-knockout mice (apoE/LDLR ${ }^{-1-}$ )
}

\author{
Magdalena Franczyk-Żarów ${ }^{1}$, Renata B. Kostogrys ${ }^{1}$, Beata Szymczyk ${ }^{2}$, Jacek Jawień ${ }^{3}$, Mariusz Gajda ${ }^{4}$, \\ Tadeusz Cichocki ${ }^{4}$, Leszek Wojnar ${ }^{5}$, Stefan Chlopicki ${ }^{3}$ and Paweł M. Pisulewski ${ }^{1 *}$ \\ ${ }^{1}$ Department of Human Nutrition, Faculty of Food Technology, Agricultural University of Kraków, ul. Balicka 122, 30-149 \\ Kraków, Poland \\ ${ }^{2}$ Department of Animal Nutrition, Institute of Animal Production, 32-083 Balice, Poland \\ ${ }^{3}$ Department of Experimental Pharmacology, Jagiellonian University Medical College, ul. Grzegórzecka 16, 31-531 \\ Kraków, Poland \\ ${ }^{4}$ Department of Histology, Jagiellonian University Medical College, ul. Kopernika 7, 31-034 Kraków, Poland \\ ${ }^{5}$ Institute of Applied Computer Science, Kraków University of Technology, al. Jana Pawla II 37, 31-864 Kraków, Poland
}

(Received 3 January 2007 - Revised 11 April 2007 - Accepted 31 May 2007)

The objective of this study was to evaluate potential anti-atherogenic properties of hen eggs enriched naturally with conjugated linoleic acid (CLA) isomers (cis-9, trans-11 and trans-10, cis-12). Eighteen apoE and LDL receptor double-knockout mice (apoE/LDLR ${ }^{-1-}$ ), at the age of 4 months with pre-established atherosclerosis, were randomly assigned to three experimental groups $(n 6)$ and fed AIN-93G-based diets for the next 2 months. The experimental diets were: AIN-93G + CLA-free egg-yolk powder (control); AIN-93G + CLA-free egg-yolk powder $+0 \cdot 1 \%$ CLA (CLA-supplemented eggs); and AIN-93G + CLA-enriched egg-yolk powder, providing 0.1\% CLA (CLA-enriched eggs). For assessment of anti-atherogenic properties of CLA-enriched or CLA-supplemented eggs the following criteria were used: (1) serum lipid profile; (2) development of atherosclerosis; and (3) composition of atherosclerotic plaque. CLA-enriched eggs, compared with CLA-supplemented eggs, reduced significantly $(P<0.05)$ total plasma cholesterol in the mice. At the same time, both CLA-supplemented eggs and CLA-enriched eggs tended to decrease the size of atherosclerotic plaque in aortic roots of mice. Most importantly, atherosclerotic plaques of mice fed CLA-enriched eggs showed significantly $(P<0.05)$ reduced number of atherogenic macrophages and increased area occupied by smooth muscle cells in atherosclerotic lesions. In conclusion, CLA-enriched eggs exerted an anti-inflammatory effect more effectively than CLA-supplemented eggs. This anti-inflammatory effect can be considered their major functional claim that warrants further exploitation.

Conjugated linoleic acid: apoE/LDLR ${ }^{-1-}$ : Atherosclerosis: Composition of aortic plaque

Conjugated linoleic acid (CLA) is a collective term to describe a class of positional and geometric isomers of linoleic acid (cis-9, cis-12 C18:2n-6) in which the two double bonds are separated by a single $\mathrm{C}-\mathrm{C}$ bond, but not by a methylene group $\left(-\mathrm{CH}_{2}-\right)$. CLA isomers are intermediate products of bacterial biohydrogenation of dietary unsaturated fatty acids in the rumen, and are mainly found in fat of ruminant milk and meat ${ }^{1}$.

In the last 10 years, extensive research have indicated that commercial CLA preparations, fed to laboratory animals, showed several health-related properties, including antiadipogenic ${ }^{2-5}$, anti-carcinogenic ${ }^{6-8}$, anti-atherogenic ${ }^{9-15}$ and anti-inflammatory ${ }^{16,17}$ effects. Consequently, in view of the evident health-related properties associated with CLA isomers and also in line with the concept of functional foods ${ }^{18}$, attempts have been made to enrich animal-derived foods with CLA isomers through animal nutrition strategies. Indeed, these attempts resulted in production of functional food such as CLA-enriched milk (butter, cheese), ruminant and non-ruminant meat, as well as eggs $19,20-23$.

Except for our preliminary studies ${ }^{24}$, there have been no data available on whether eggs, enriched naturally with CLA isomers, and fed to laboratory animals, could have healthrelated properties similar to those described for CLA isomers fed in free forms. Therefore, the major objective of the present study was to verify the potential health-related,

Abbreviations: apoE/LDLR ${ }^{-1-}$ mice, apoE and LDL receptor double-knockout mice; CLA, conjugated linoleic acid; HDL-C, HDL-cholesterol, LDL-C, LDLcholesterol; SMA, anti-smooth muscle $\alpha$-actin; TC, total cholesterol.

* Corresponding author: Prof. Paweł M. Pisulewski, fax +48 1266248 12, email rrpisule@cyf-kr.edu.pl 
namely anti-atherogenic, potency of CLA-enriched eggs, fed to apoE and LDL receptor double-knockout mice (apoE/ $\mathrm{LDLR}^{-/-}$), representing a unique and reliable model of atherogenesis ${ }^{25-27}$. We fed laying hens with commercial CLA mixture in a manner that allowed production of CLA-enriched eggs $^{28,29}$. Subsequently, the eggs (egg yolks) were given to apoE/LDLR ${ }^{-1-}$ mice with pre-established atherosclerosis. Anti-atherogenic properties of CLA-enriched eggs were compared with those of CLA-supplemented eggs, using the following criteria: (1) serum lipid profile; (2) development of atherosclerosis; and (3) composition of atherosclerotic plaque.

\section{Materials and methods}

\section{Production of conjugated linoleic acid-enriched eggs}

The feeding conditions to obtain CLA-enriched eggs were essentially the same as described previously ${ }^{28}$. In order to determine the optimum concentration of dietary CLA, laying hens were assigned to five modified commercial layer diets, containing sunflower and rapeseed oils (20 and $40 \mathrm{~g} / \mathrm{kg}$, respectively), and the following graded levels of CLA oil $(\mathrm{g} / \mathrm{kg}): 0,2 \cdot 5,5 \cdot 0,7 \cdot 5$ and 10 . The CLA oil (Luta-CLA $\left.{ }^{\circledR} 60\right)$, obtained from BASF (Ludwigshafen, Germany), contained $600 \mathrm{~g} \mathrm{CLA} / \mathrm{kg}$, with equal representation of two major CLA isomers (cis-9, trans-11 and trans-10, cis-12). The CLA oil was substituted for an appropriate amount of sunflower oil to obtain the required CLA concentrations. After 4 weeks of feeding, eggs were collected and egg yolks analysed for fatty acids using a Shimadzu GC-MS analyser (Model QP 5050A; Shimadzu Corporation, Kyoto, Japan) Table 1. In addition, the eggs collected after 4 weeks were hard-boiled, egg yolks were separated and their hardness was evaluated on a Stable Micro Systems texture analyser (Model TA-XT2; Leeds UK) Table 2. In view of the obtained results, the optimum dietary CLA concentration in laying hen diets, for nutritional enrichment of hen eggs, was arbitrarily chosen to be $7.5 \mathrm{~g} / \mathrm{kg}$. Consequently, the laying hens were then fed the CLA-free $(0 \mathrm{~g} / \mathrm{kg})$ and CLA-supplemented $(7.5 \mathrm{~g} / \mathrm{kg})$ diets to produce an appropriate amount of freezedried CLA-free and CLA-enriched egg yolks, to be included into AIN-93G diets fed to apoE/LDLR ${ }^{-/-}$mice.

\section{Animals and housing}

The apoE/LDLR ${ }^{-/-}$mice used in the present study ${ }^{30}$ were obtained from the Cardiovascular Research Institute Maastricht, Maastricht University (Maastricht, The Netherlands) and bred in the animal house in Warszawa (Polish Academy of Science, Medical Research Centre). Animals were housed in colony cages in a temperature-controlled environment $\left(22-25^{\circ} \mathrm{C}\right)$ with a $12 \mathrm{~h}$ light cycle. They had free access to food and water.

All procedures involving animals were conducted according to the Guidelines for Animal Care and Treatment of the European Union and were approved by the Local Animal Ethics Committee.

\section{Diets and feeding}

Up to the age of 4 months, the mice were fed a commercial, cholesterol-free, pelleted diet (Sniff M-Z Spezialdiäten $\mathrm{GmbH}$, Soest, Germany). Diet and water, consumed ad libitum, were regularly checked and provided daily.

At the age of 4 months, mice ( $n 18$ ) were randomly assigned to three experimental groups ( $n$ 6) and fed AIN-93G-based diets $^{31}$ for the next 2 months.

The experimental diets were the following: (I) AIN-93G + CLA-free egg-yolk powder (control); (II) AIN-93G + CLA-free egg-yolk powder $+0.1 \%$ CLA (CLA-supplemented eggs); and (III) AIN-93G + CLA-enriched egg-yolk powder providing

Table 1. Effect of feeding hens with conjugated linoleic acid (CLA)-enriched diets $(0,2.5,5.0,7.5$ and $10 \mathrm{~g} / \mathrm{kg})$ on fatty acid composition (relative \%) of egg-yolk lipids after 4 weeks of experiment

(Mean values with their standard errors)

\begin{tabular}{|c|c|c|c|c|c|c|c|c|c|c|}
\hline \multirow[b]{3}{*}{ Fatty acids } & \multicolumn{10}{|c|}{ Dietary level of CLA $(\mathrm{g} / \mathrm{kg})$} \\
\hline & \multicolumn{2}{|c|}{0} & \multicolumn{2}{|c|}{2.5} & \multicolumn{2}{|c|}{5} & \multicolumn{2}{|c|}{7.5} & \multicolumn{2}{|c|}{10} \\
\hline & Mean & SEM & Mean & SEM & Mean & SEM & Mean & SEM & Mean & SEM \\
\hline C14:0 & $0.3^{a}$ & 0.07 & $0.4^{\mathrm{b}}$ & 0.00 & $0.5^{c}$ & 0.07 & $0.5^{c}$ & 0.00 & $0.5^{c}$ & 0.07 \\
\hline C16:0 & $21 \cdot 8^{\mathrm{a}}$ & 0.32 & $25 \cdot 3^{\mathrm{b}}$ & 0.34 & $27 \cdot 9^{c}$ & 0.26 & $27 \cdot 7^{c}$ & 0.39 & $26 \cdot 5^{b}$ & 0.37 \\
\hline C16: 1 & $2 \cdot 9^{\mathrm{a}}$ & $0 \cdot 15$ & $1 \cdot 7^{\mathrm{b}}$ & 0.13 & $1.5^{\mathrm{c}}$ & 0.13 & $1 \cdot 2^{d}$ & 0.07 & $1 \cdot 1^{\mathrm{d}}$ & 0.11 \\
\hline C17:0 & $0.2^{\mathrm{a}}$ & 0.07 & $0.3^{\mathrm{b}}$ & 0.00 & $0.3^{\mathrm{b}}$ & 0.07 & $0.3^{\mathrm{b}}$ & 0.07 & $0.4^{\mathrm{c}}$ & 0.07 \\
\hline C18:0 & $7 \cdot 7^{\mathrm{a}}$ & 0.18 & $10 \cdot 5^{\mathrm{b}}$ & 0.21 & $12 \cdot 7^{\mathrm{c}}$ & 0.26 & $14 \cdot 4^{d}$ & 0.32 & $14 \cdot 6^{\mathrm{d}}$ & 0.24 \\
\hline C18: 1 & $46 \cdot 8^{a}$ & 0.36 & $39 \cdot 5^{\mathrm{b}}$ & 0.28 & $36 \cdot 5^{\mathrm{c}}$ & 0.33 & $35 \cdot 2^{\mathrm{cd}}$ & 0.33 & $34 \cdot 7^{d}$ & 0.23 \\
\hline C18:2 & $14 \cdot 9^{a}$ & 0.30 & $16 \cdot 5^{\mathrm{b}}$ & 0.20 & $14 \cdot 8^{a}$ & 0.24 & $14 \cdot 7^{a}$ & 0.28 & $14 \cdot 6^{a}$ & 0.03 \\
\hline C18:3 & $0.9^{a}$ & 0.09 & $1 \cdot 2^{b}$ & 0.07 & $1 \cdot 1^{\mathrm{b}}$ & 0.07 & $1 \cdot 2^{\mathrm{b}}$ & 0.07 & $1.4^{\mathrm{c}}$ & 0.09 \\
\hline $\mathrm{C} 20: 4$ & $1.9^{a}$ & 0.15 & $1 \cdot 7^{\mathrm{ab}}$ & 0.14 & $1.5^{\mathrm{b}}$ & 0.09 & $1.4^{\mathrm{b}}$ & 0.13 & $1 \cdot 5^{\mathrm{b}}$ & 0.15 \\
\hline $\mathrm{C} 22: 5$ & $0 \cdot 1^{a}$ & 0.07 & $0 \cdot 2^{b}$ & 0.07 & $0.3^{c}$ & 0.07 & $0 \cdot 3^{c}$ & 0.07 & $0.3^{c}$ & 0.06 \\
\hline C22: 6 & $1.4^{\mathrm{a}}$ & $0 \cdot 10$ & $1 \cdot 2^{\mathrm{b}}$ & 0.10 & $1.0^{c}$ & 0.00 & $0.9^{c}$ & 0.08 & $0.9^{c}$ & 0.07 \\
\hline \multicolumn{11}{|l|}{ CLA isomers } \\
\hline cis- 9, trans- 11 & $0.00^{a}$ & & $0.6^{\mathrm{b}}$ & 0.07 & $0.9^{c}$ & 0.00 & $1 \cdot 2^{d}$ & 0.07 & $2 \cdot 0^{\mathrm{e}}$ & 0.17 \\
\hline trans -10, cis -12 & $0.00^{\mathrm{a}}$ & & $0.1^{\mathrm{b}}$ & 0.00 & $0.2^{c}$ & 0.06 & $0.5^{d}$ & 0.07 & $0.9^{e}$ & 0.07 \\
\hline Total SFA & $30 \cdot 4^{a}$ & 0.31 & $36 \cdot 3^{b}$ & 0.39 & $41.6^{c}$ & 0.38 & $43 \cdot 1^{\mathrm{c}}$ & 0.50 & $41 \cdot 7^{\mathrm{c}}$ & 0.13 \\
\hline Total MUFA & $50 \cdot 1^{a}$ & 0.31 & $42 \cdot 1^{\mathrm{b}}$ & 0.30 & $37 \cdot 9^{c}$ & 0.27 & $36 \cdot 6^{d}$ & 0.31 & $36 \cdot 5^{d}$ & 0.37 \\
\hline Total PUFA & $19 \cdot 5^{a}$ & 0.36 & $21 \cdot 6^{b}$ & 0.29 & $19 \cdot 5^{a}$ & 0.32 & $20 \cdot 3^{a}$ & 0.37 & $21 \cdot 8^{b}$ & 0.40 \\
\hline
\end{tabular}

${ }^{a-e}$ Mean values within a row with unlike superscript letters were significantly different $(P<0.001$; Duncan's multiple range test). 
Table 2. Effect of feeding hens with conjugated linoleic acid (CLA)-enriched diets $(0,2 \cdot 5,5 \cdot 0,7 \cdot 5$ and $10 \mathrm{~g} / \mathrm{kg})$ and days of refrigeration on egg characteristics and egg yolk hardness after 4 weeks of experiment

(Mean values for CLA dietary level and days of refrigeration with their standard errors)

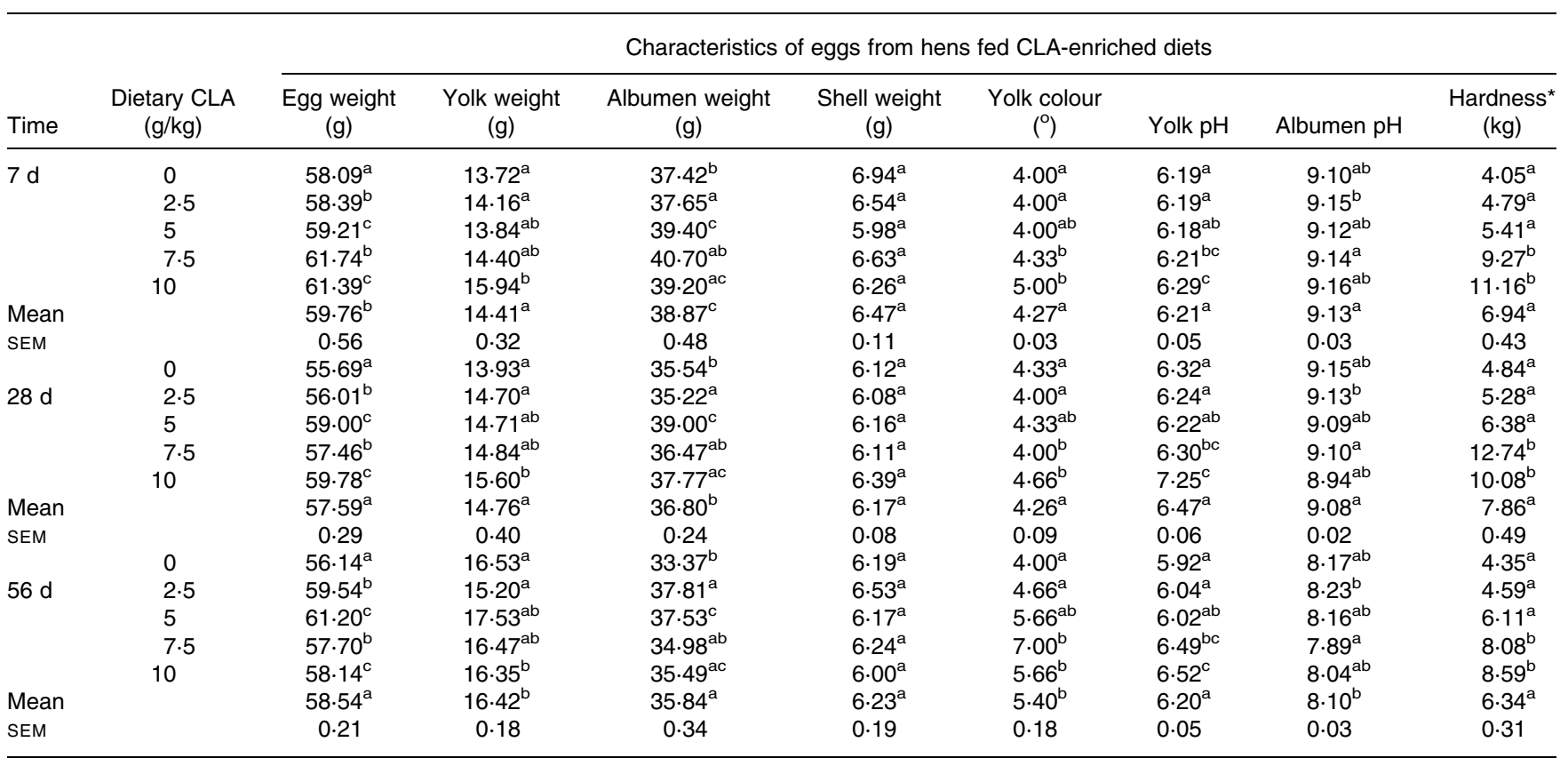

${ }^{a, b, c}$ Mean values for CLA dietary level effect within a column with unlike superscript letters were significantly different $(P<0 \cdot 05$; Duncan's multiple range test).

*Hardness determined for hard-boiled egg yolks using a Stable Micro Systems TA-XT2 texture analyser.

Ð $\quad 0.1 \%$ CLA incorporated into egg-yolk lipids (CLA-enriched eggs). The detailed composition of these three experimental AIN-93G-based diets is shown in Table 3.

After 2 months of feeding with respective diets, the mice were deprived of food overnight, injected intraperitoneally with 1000 IU heparin (Sanofi-Synthelabo, Paris, France), and after $10 \mathrm{~min}$, anaesthetized intraperitoneally with $40 \mathrm{mg}$ sodium thiopental $/ \mathrm{kg}$ (Biochemie, Vienna, Austria), and finally killed by cervical translocation.

\section{Blood sampling and plasma lipid profile analyses}

Blood samples were taken from the left ventricle of the heart, collected into test tubes and centrifuged $(4000 \mathrm{~g}, 10 \mathrm{~min})$ to obtain plasma samples. The samples were deep frozen $\left(-80^{\circ} \mathrm{C}\right)$ and stored until further analysis. Plasma samples were analysed using commercially available kits for total cholesterol (TC; Liquick Cor-Chol 60 no. 2-204; Cormay, Lublin, Poland), LDL-cholesterol (LDL-C; no. OSR 6183; Olympus Diagnostica GmbH, Hamburg, Germany), HDL-cholesterol (HDL-C; no. OSR 6287; Olympus) and TAG (Liquick Cor-TG 30 no. 2-262; Cormay). The results are expressed in $\mathrm{mmol} / \mathrm{l}$.

\section{Quantitation of atherosclerosis in aortic roots (cross-section analysis)}

In anaesthetized mice, the thorax was longitudinally opened, the right atrium was incised and the heart was perfused by PBS ( $\mathrm{pH} \mathrm{7.4)} \mathrm{through} \mathrm{the} \mathrm{apex} \mathrm{of} \mathrm{the} \mathrm{left} \mathrm{ventricle} \mathrm{at}$

Table 3. Composition of the AIN-93G-based diets $(\mathrm{g} / \mathrm{kg})$ fed to apoE and LDL receptor double-knockout $\left(\right.$ apoE/LDLR $\left.{ }^{-1-}\right)$ mice

\begin{tabular}{|c|c|c|c|}
\hline Ingredient & Group I (control) & Group II (CLA-supplemented eggs) & Group III (CLA-enriched eggs) \\
\hline Cornstarch & $482 \cdot 49$ & $480 \cdot 82$ & 482.49 \\
\hline Casein & 150 & 150 & 150 \\
\hline Sucrose & 100 & 100 & 100 \\
\hline Soyabean oil & - & - & - \\
\hline Fibre & 50 & 50 & 50 \\
\hline Mineral mix & 35 & 35 & 35 \\
\hline Vitamin mix & 10 & 10 & 10 \\
\hline Choline & 2.5 & 2.5 & $2 \cdot 5$ \\
\hline TBHQ & 0.014 & 0.014 & 0.014 \\
\hline CLA & - & 1.67 & - \\
\hline CLA-free egg yolks & 170 & 170 & - \\
\hline CLA-enriched egg yolks & - & - & 170 \\
\hline Total & 1000 & 1000 & 1000 \\
\hline
\end{tabular}

CLA, conjugated linoleic acid; TBHQ, Tert-buty Ihydroquinone. 
a constant pressure of approximately $100 \mathrm{mmHg}$. Next, the heart and the ascending aorta were dissected. The excised heart and ascending aorta were embedded in OCT compound (CellPath, Oxford, UK) and snap-frozen. Cryosections (10 $\mu \mathrm{m}$ thick) were cut from the aortic root using a standardized protocol $^{32,33}$. Serial sections were cut from the proximal $1 \mathrm{~mm}$ of the aortic root. Eight sections were collected at $100 \mu \mathrm{m}$ intervals starting at a $100 \mu \mathrm{m}$ distance from the appearance of the aortic valves. Sections were thaw-mounted on poly-L-lysine-coated slides and air dried. After fixation in $4 \%$ paraformaldehyde ( $\mathrm{pH} \mathrm{7)}$, sections were stained with Meyer's haematoxylin and oil red-O (Sigma-Aldrich, St Louis, MO, USA) ${ }^{34}$. Oil red-O-stained sections were examined under an Olympus BX50 (Olympus, Tokyo, Japan) microscope and used for quantitative evaluation. Images of the aorta were recorded using an Olympus Camedia 5050 digital camera and stored as TIFF files of resolution $1024 \times 768$ pixels. The total area of the lesion was measured semi-automatically in each slide using LSM Image Browser 3 software (Zeiss, Jena, Germany). For each animal a mean lesion area was calculated from eight sections, reflecting the cross-section area covered by atherosclerosis $^{34}$.

\section{Quantification of atherosclerosis in descending aortas (en face} analysis)

The aorta from arch to bifurcation was dissected out from surrounding tissues and fixed in $4 \%$ formaldehyde. Then it was opened longitudinally, pinned on to brown silicone plates and stained with Sudan IV (Sigma-Aldrich). The aortic lesion area and total aortic area were measured fully automatically using specially designed algorithm and Aphelion software. Images of the aorta were recorded using a digital camera as RGB colour images. The images obtained were binarized on the basis of colour distribution in two areas of interested selected automatically at the image edges, i.e. outside the aorta. The resulting binary image was additionally filtered using mathematical morphology operations in order to remove small holes, traces of needles and other artifacts. In turn, the aortic lesion area was detected automatically using the minimum entropy criterion on grey-scale images, being a difference between the red and blue components of the initial image.

\section{Analysis of atherosclerotic plaques composition by immunohistochemistry}

For indirect immunohistochemistry, acetone-fixed cryosections of ascending aorta were used. Sections were cut and collected as described earlier. They were incubated overnight with primary antisera: Cy3-conjugated anti-smooth muscle $\alpha$-actin (SMA; Sigma-Aldrich; diluted 1:600), rat antimouse CD68 (Serotec, Oxford, UK; diluted 1:800). Then, goat anti-rat IgG biotinylated antibodies were applied followed by DTAF-conjugated streptavidin (both from Jackson IR, West Grove, PA, USA). Sections were examined using an epifluorescence Olympus BX50 microscope equipped with appropriate filter cubes to show $\mathrm{Cy} 3$ (red), and DTAF (green) fluorescence for SMA and CD68, respectively. The images were registered with a Camedia 5050 digital camera.
In each section, the total area occupied by CD68-immunopositive macrophages was measured semi-automatically using LSM Image Browser software and expressed as a percentage of the whole area of atherosclerotic plaque. Atherosclerotic plaques with a continuous layer of SMA-positive cells at the internal part of the plaque were also counted and expressed as a percentage of the whole area of atherosclerotic plaque.

\section{Statistical analysis}

Results are expressed as means and their standard errors. Where appropriate, the data were subjected to one-way ANOVA generated by the Statistica version 6.1 package (StatSoft Inc., Tulsa, OK, USA), followed by post-hoc Duncan's multiple range test. The differences between treatment means were considered significant at $P<0 \cdot 05$. The data resulting from quantification of atherosclerosis were analysed by the non-parametric Mann-Whitney test and differences between treatment means were considered significant at $P<0 \cdot 05$.

\section{Results}

\section{Effect of conjugated linoleic acid-supplemented and conjugated linoleic acid-enriched eggs on plasma lipid profile}

The effect of dietary treatments on plasma lipoprotein concentrations is shown in Fig. 1. The only evident effect of dietary treatments was the reduction of plasma TC in mice fed CLAenriched eggs as compared to the effect of CLA-supplemented eggs $(P<0.05)$. At the same time, dietary treatments had no significant effects on individual plasma lipoproteins. The same was true for plasma TAG.

\section{Effect of conjugated linoleic acid-supplemented and} conjugated linoleic acid-enriched eggs on the development of atherosclerosis

Area of atherosclerosis as measured in whole aorta (en face) by Sudan IV staining was not different between experimental groups (Figs. 2 and 3). Also area of plaques as measured in

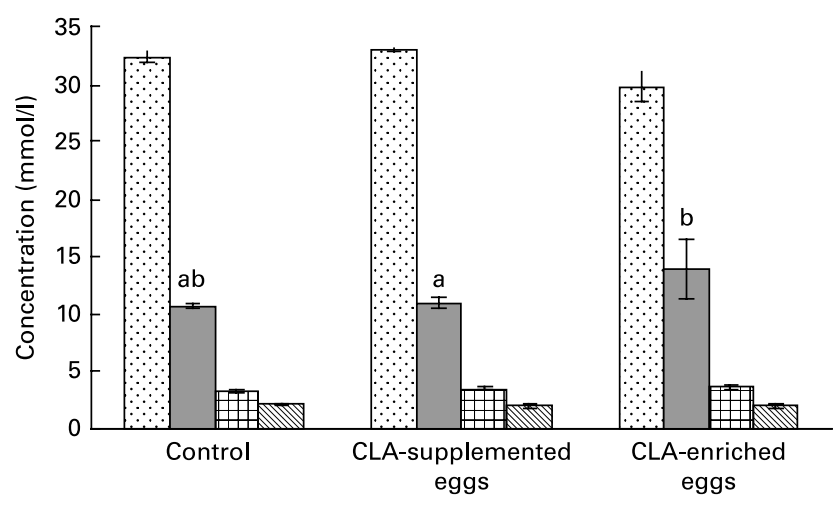

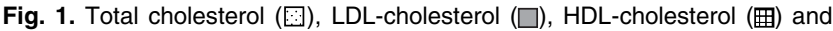

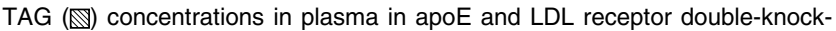
out mice (apoE/LDLR ${ }^{-/-}$) fed control, conjugated linoleic acid (CLA)-supplemented and CLA-enriched eggs. Values are means with their standard errors depicted by vertical bars. ${ }^{a, b}$ Mean values with unlike letters were significantly different $(P<0.05$; Duncan's multiple range test). 


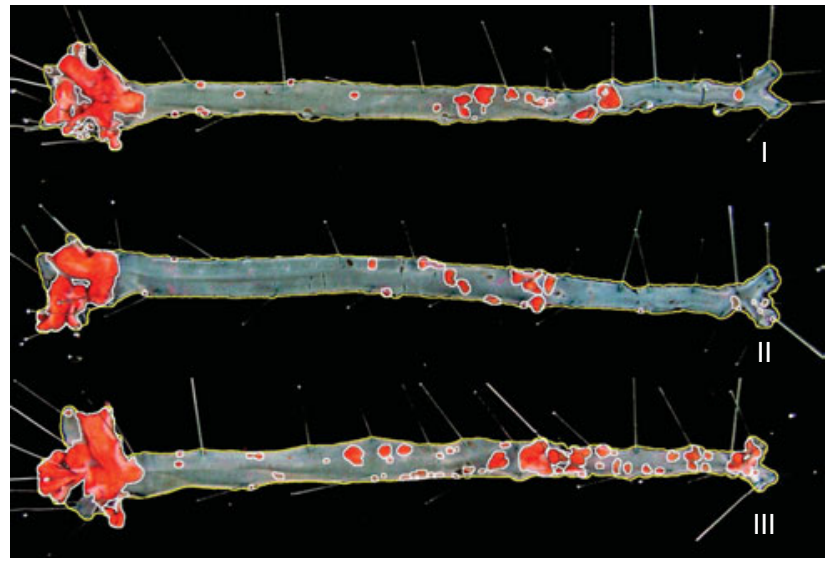

Fig. 2. Representative images of en face aorta showing atherosclerotic plaque in apoE and LDL receptor double-knockout mice (apoE/LDLR ${ }^{-1-}$ ) fed control (I), conjugated linoleic acid (CLA)-supplemented (II) and CLAenriched (III) eggs.

aortic roots (cross-section) did not differ significantly between experimental groups (Figs. 4 and 5). However, in apoE/ LDLR $^{-1-}$ mice fed CLA-supplemented or CLA-enriched eggs, the area of plaques tended to be lower as compared to the control group (1075661 v. $1366832 \mu \mathrm{m}^{2}$ and 1209342 v. $1366832 \mu \mathrm{m}^{2}$, respectively).

Interestingly, despite the lack of significant effects of CLAsupplemented or CLA-enriched eggs on the size of atherosclerotic plaque, the diet containing CLA-enriched eggs had a pronounced effect $(P<0 \cdot 05)$ on macrophage accumulation in atherosclerotic plaques as determined by immunohistochemical staining for a specific macrophage marker (CD68). Indeed, as shown in Fig. 6, the plaque area covered by macrophages in mice fed control and CLA-enriched diet was 60.9 and $32 \%$, respectively. In contrast, in mice fed CLA-supplemented eggs such an effect could not be seen.

The opposite changes were observed as regards area covered by SMA-positive cells in aortic plaques (Fig. 7). Indeed, the area covered by SMA-positive cells in aortic plaques was increased in mice fed CLA-enriched diet

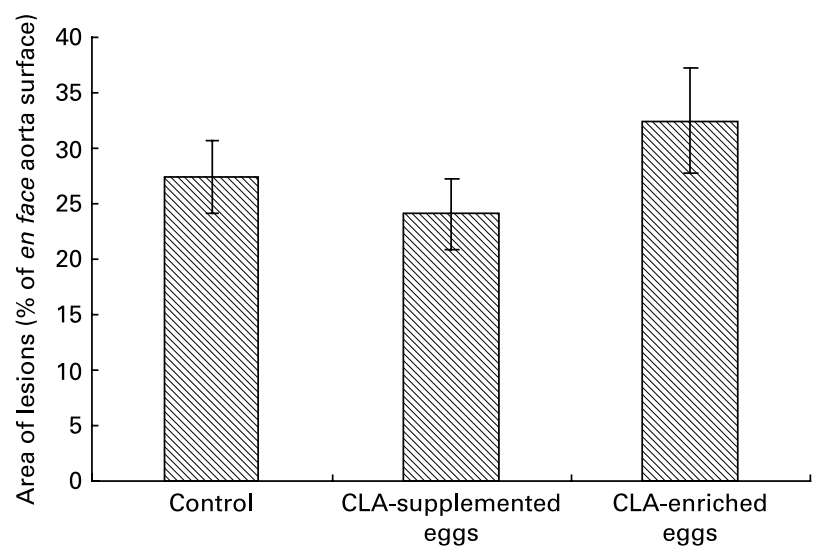

Fig. 3. Quantification ( $\%$ area) of atherosclerotic plaque in entire aorta (en face) in apoE and LDL receptor double-knockout mice (apoE/LDLR ${ }^{-1-}$ ) fed control, conjugated linoleic acid (CLA)-supplemented and CLA-enriched eggs. Values are means with their standard errors depicted by vertical bars.
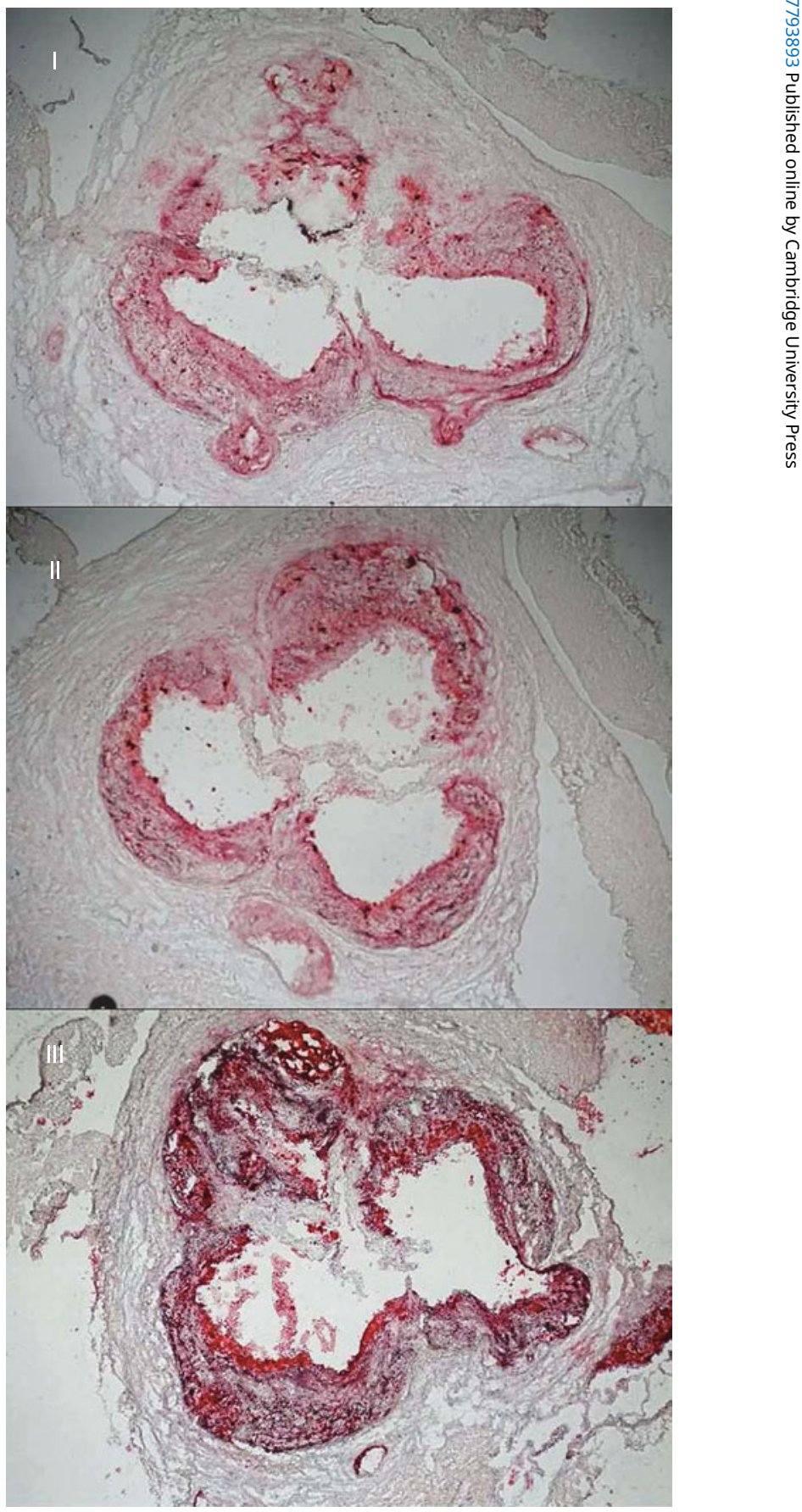

Fig. 4. Representative images of cross-sections of aortic roots showing aortic plaque in apoE and LDL receptor double-knockout mice (apoE/LDLR ${ }^{-1-}$ ) fed control (I), conjugated linoleic acid (CLA)-supplemented (II) and CLAenriched (III) eggs.

as compared to the control diet. Again, no such effect was noticed for CLA-supplemented diet. The present findings are considered to indicate that the diet containing CLAenriched eggs, but not the one containing CLA-supplemented eggs, displays anti-inflammatory, anti-atherosclerotic effects characterized by a decreased occurrence of macrophages and increased presence of smooth muscle cells in the atherosclerotic plaques. 


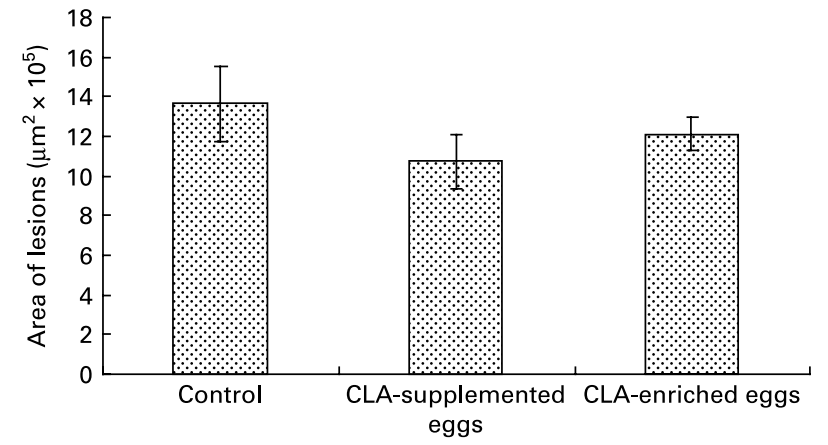

Fig. 5. Quantification $\left(\mu \mathrm{m}^{2}\right)$ of atherosclerotic plaque area in aortic roots (cross-section) in apoE and LDL receptor double-knockout mice (apoE/LDLR ${ }^{-/-}$) fed control, conjugated linoleic acid (CLA)-supplemented and CLA-enriched eggs. Values are means with their standard errors depicted by vertical bars.

\section{Discussion}

The objective of the present study was to examine potential anti-atherogenic effects of eggs (egg yolks) naturally enriched with CLA isomers. In line with the concept of functional foods ${ }^{18,35,36}$, the present discussion will examine the eggs (egg yolks) naturally enriched with CLA isomers according to whether they: (1) can be considered conventional foods; (2) can be consumed as a part of a normal diet; (3) are composed of naturally occurring components; (4) have a positive effect on target function(s) beyond nutritive value; (5) enhance health and/or reduce the risk of disease; and (6) have scientifically based claims.

The present study clearly indicates that eggs naturally enriched with CLA isomers (as derived in the present experiment) preserve generally their composition and conventional properties (Tables 1 and 2). However, it should be indicated that increasing dietary CLA concentrations $(0 \cdot 0-1.0 \%)$ led to increased concentrations of CLA in egg-yolk lipids.
Moreover, cis-9, trans-11 CLA was incorporated into eggyolk lipids more efficiently than trans-10, cis-12 CLA. It should be also indicated that increasing dietary CLA concentrations altered relative proportions of SFA and MUFA in eggyolk lipids (Tables 1 and 4). Namely the proportions of SFA (e.g. 16:0 and 18:0) were increased $(P<0 \cdot 01)$, those of MUFA (e.g. 18:1n-9) decreased $(P<0 \cdot 01)$, whereas concentrations of PUFA were not affected. Generally, when compared with the results of our earlier studies using much higher dietary concentrations of CLA (e.g. $0 \cdot 0-2 \cdot 0 \%{ }^{28}$ ), the changes noted in the present experiment were largely attenuated. Interestingly, the present inverse changes between SFA and MUFA concentrations tended to level off at the concentration of dietary CLA reaching $0.75 \%$. Moreover, dietary CLA had no apparent effects on sensory parameters of eggs (Table 2) during refrigerated storage $\left(7,28\right.$ and $\left.56 \mathrm{~d} ; 4^{\circ} \mathrm{C}\right)$. Thus, the present observations could be attributed to the period of the storage. On the other hand, dietary CLA increased consistently the firmness of hard-boiled egg yolks, notably at the concentrations of 0.75 and $1.0 \%$ CLA, at which it tended to level off. In view of the present results we have arbitrarily chosen the dietary concentration of $0.75 \%$ CLA as the optimum for laying hens, to enrich effectively hen egg yolks with CLA. The present results are generally consistent with the earlier findings and were thoroughly discussed and elucidated by Schäfer et al. ${ }^{37}$, Raes et al. ${ }^{38}$, Szymczyk \& Pisulewski ${ }^{28}$, and more recently by Shang et $a l .{ }^{39}$ and Cachaldora et al. ${ }^{40}$.

The CLA-enriched eggs, as derived in the present experiment and considered to preserve the conventional properties of hen eggs, can be consumed as a part of the normal human diet. In fact, the concept of functional foods (i.e. nutritionally enhanced eggs) has been already advocated by Hasler ${ }^{41}$. As emphasized by Raes et al. ${ }^{38}$, these eggs can be considered a good source of CLA isomers, supplementing those derived from ruminant products (milk and meat), naturally rich in CLA. What is more, the functional eggs, naturally

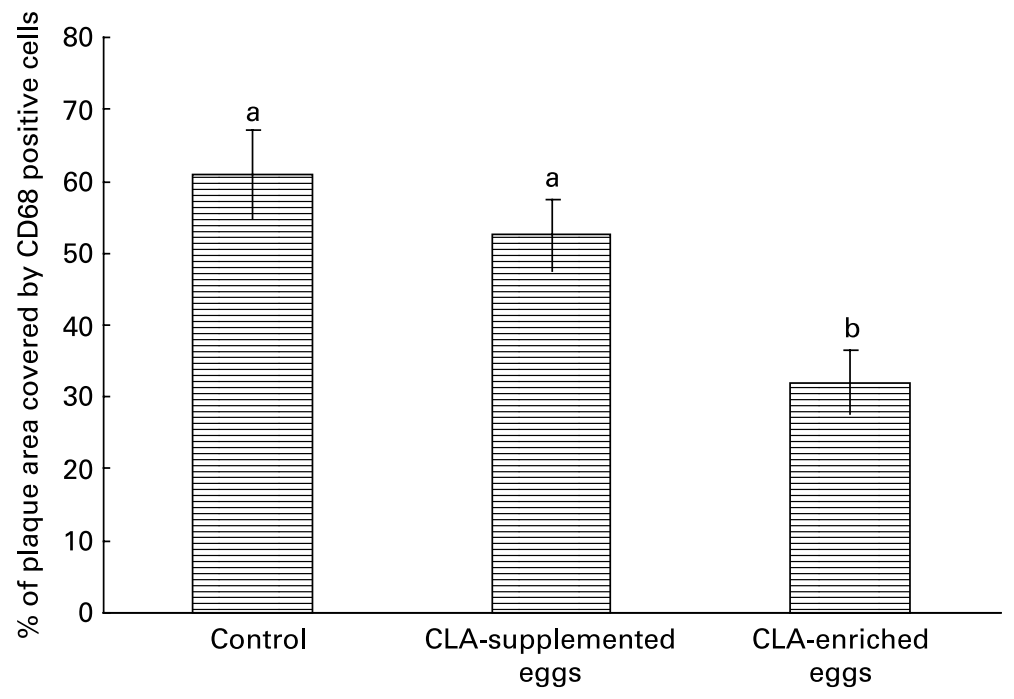

Fig. 6. Quantification (\%) of macrophage accumulation in atherosclerotic plaque (cross-sections) as determined by immunohistochemical staining for a specific macrophage marker (CD68) in in apoE and LDL receptor double-knockout mice (apoE/LDLR ${ }^{-1-}$ ) fed control, conjugated linoleic acid (CLA)-supplemented and CLA-enriched eggs. Values are means with their standard errors depicted by vertical bars. ${ }^{\mathrm{a}, \mathrm{b}}$ Mean values with unlike letters were significantly different $(P<0.05$; non-parametric Mann-Whitney test). 


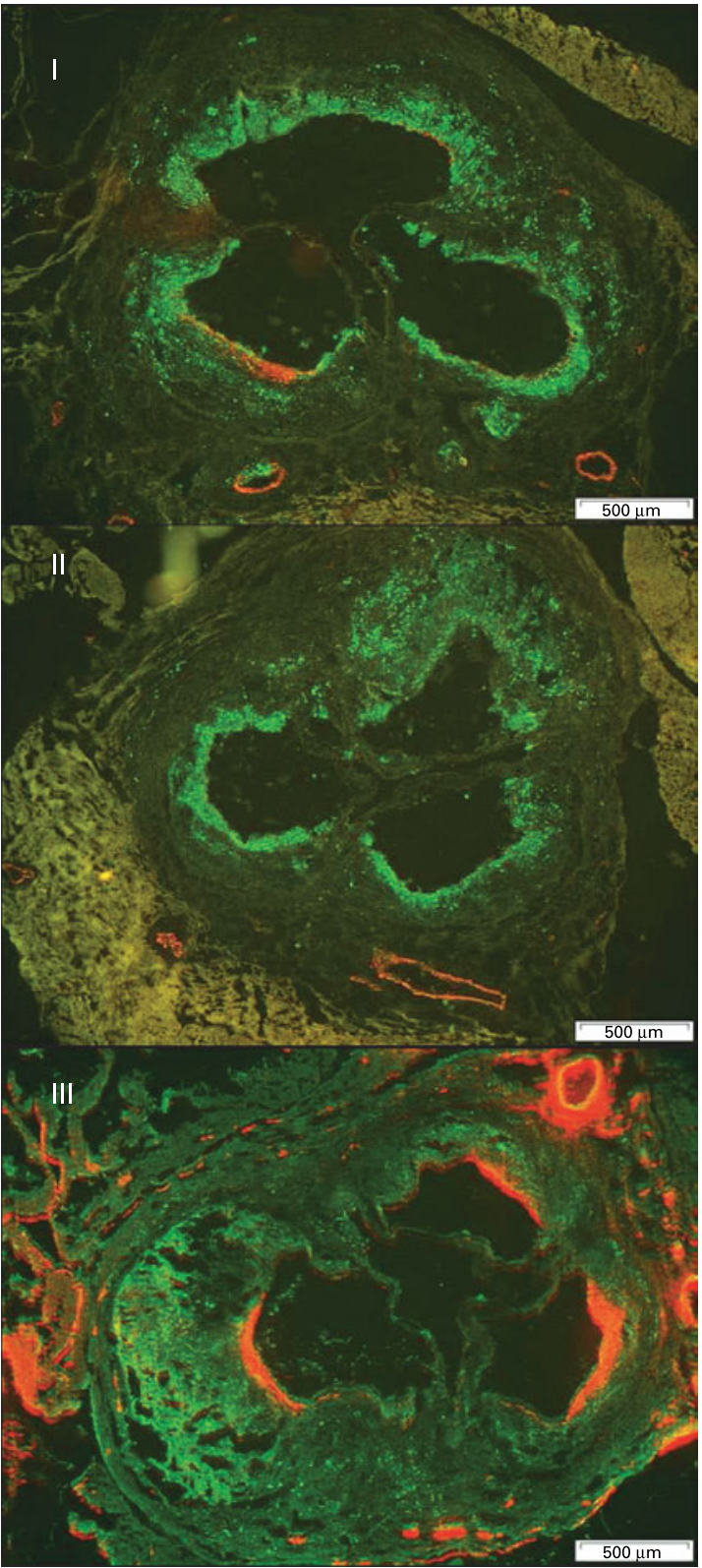

Fig. 7. Representative images of aortic roots (cross-sections) stained for a specific macrophage marker (CD68; green fluorescence) and anti-smooth muscle $\alpha$-actin-positive cells (red fluorescence) in apoE and LDL receptor double-knockout mice (apoE/LDLR ${ }^{-/-}$) fed control (I), conjugated linoleic acid (CLA)-supplemented (II) and CLA-enriched (III) eggs.

enriched with $n$-3 PUFA, are currently commercialized in Europe and in the USA. Therefore, the consumption of functional eggs enriched naturally with both CLA and n-3 PUFA in usual human diets is fully feasible $\mathrm{e}^{38,42}$.

The CLA-enriched eggs (as derived in the present experiment), are becoming a good source of naturally occurring components, i.e. CLA isomers, showing several health-related properties (see Introduction). Generally, the predominant CLA isomers in ruminant fat are cis-9, trans-11 CLA, that accounts for more than $80 \%$ of total isomers, and trans-10, cis- $12 \mathrm{CLA}^{1}$. In the CLA preparations currently available, two isomers, i.e. cis-9, trans11 and trans-10, cis-12 CLA, usually predominate and are represented in equal amounts, whereas the older CLA preparations
Table 4. Effect of feeding hens with conjugated linoleic acid (CLA)-enriched diets ( 0 and $7.5 \mathrm{~g} / \mathrm{kg}$ ) on fatty acid composition (relative \%) of egg-yolk lipids (egg yolks destined to be freeze-dried and fed to apoE and LDL receptor double-knockout (apoE/LDLR ${ }^{-/-}$) mice

\begin{tabular}{|c|c|c|}
\hline \multirow[b]{2}{*}{ Fatty acid composition } & \multicolumn{2}{|c|}{ CLA g/kg } \\
\hline & 0 & $7 \cdot 5$ \\
\hline $10: 0$ & - & - \\
\hline $12: 0$ & - & - \\
\hline $14: 0$ & 0.3 & 0.4 \\
\hline $14: 1$ & 0.1 & - \\
\hline $15: 0$ & 0.1 & 0.1 \\
\hline $16: 0$ & $21 \cdot 1$ & $25 \cdot 1$ \\
\hline $16: 1$ cis-7 & $1 \cdot 1$ & 0.7 \\
\hline $16: 1$ cis-9 & $1 \cdot 8$ & 0.7 \\
\hline $17: 0$ & 0.2 & 0.4 \\
\hline $17: 1$ & 0.1 & 0.1 \\
\hline $18: 0$ & $7 \cdot 7$ & $12 \cdot 8$ \\
\hline $18: 1$ trans & 0.1 & 0.2 \\
\hline $18: 1$ cis-9 & $43 \cdot 6$ & $35 \cdot 7$ \\
\hline $18: 1$ cis-11 & 1.9 & $1 \cdot 3$ \\
\hline $18: 2$ trans & 0.1 & 0.1 \\
\hline $18: 2$ & $16 \cdot 7$ & $16 \cdot 2$ \\
\hline $18: 3$ trans & 0.1 & 0.1 \\
\hline $18: 3$ & $1 \cdot 1$ & $1 \cdot 2$ \\
\hline $18: 2$ cis -9, trans $-11^{*}$ & 0.03 & 1.05 \\
\hline $18: 2$ trans -10, cis $-12 \dagger$ & - & 0.24 \\
\hline $20: 1$ & 0.3 & 0.3 \\
\hline $20: 2$ & 0.1 & 0.1 \\
\hline $20: 3$ & 0.1 & 0.1 \\
\hline $20: 4$ & 1.9 & 1.5 \\
\hline $22: 4$ & 0.1 & 0.1 \\
\hline $22: 5$ & 0.1 & 0.3 \\
\hline $22: 6$ & 1.2 & $1 \cdot 1$ \\
\hline
\end{tabular}

*Concentration of cis-9, trans-11 CLA isomer in freeze-dried egg

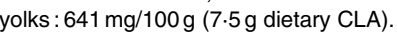

†Concentration of trans-10, cis-12 CLA isomer in freeze-dried egg yolks : $143 \mathrm{mg} / 100 \mathrm{~g}(7.5 \mathrm{~g}$ dietary CLA).

contained also trans- 8 , cis-10 and cis-11, trans- 13 CLA $^{43}$. Therefore, the use of a current product (Luta-CLA ${ }^{\circledR} 60$ ) in the present studies decreased the risk of incorporation of CLA isomers of unknown biological activity into egg-yolk lipids. What is more, the ratio of cis-9, trans-11 to trans-10, cis-12 isomers in freezedried egg yolks was $80: 20$, thus reflecting the ratio of these isomers in natural sources of CLA (e.g. milk fat). This preferential incorporation of cis-9, trans-11 isomer into egg-yolk lipids has been already reported by Raes et $a l^{38}$ and Szymczyk \& Pisulewski ${ }^{28}$.

As recommended by Aggett et al. ${ }^{18}$, the beneficial healthrelated effects of CLA-enriched eggs were evaluated using three types of biological marker: (1) markers of exposure to a biologically active food component; (2) markers of biological response; and (3) markers of intermediate end-point.

In the present experiment carried out on apoE/LDLR ${ }^{-/-}$ mice, we have not evaluated the degree of exposure of the mice to dietary CLA isomers by measuring the CLA concentrations in body fluids. However, feeding CLA isomers to man was clearly reflected by elevated blood concentration of $\mathrm{CLA}^{44,45}$. What is more, CLA isomers were most probably incorporated into egg-yolk phospholipids, and as such, could have been more efficiently absorbed, compared with their absorption from $\mathrm{TAG}^{46}$. 
Among the markers of biological response, the serum lipid profile of the experimental mice was evaluated in detail. Generally, the serum lipid profile was typical for our animal model, i.e. apoE/LDLR ${ }^{-1-30}$. However, the present studies produced equivocal results. In the mice fed CLA-enriched eggs, total plasma cholesterol was significantly $(P<0 \cdot 05)$ decreased (Fig. 1). In contrast, concentrations of individual plasma lipoproteins were not affected and only tended to increase (LDL-C and HDL-C) or decrease (TAG). The results of early studies, using CLA commercial oils, are also inconclusive. In an early experiment of Lee et $a l .{ }^{47}$, CLA treatment decreased TC and LDL-C, as well as plasma TAG in rabbits. Also, in studies of Nicolosi et al. ${ }^{48}$, the hamsters fed CLA showed significantly reduced levels of plasma TC, LDL$\mathrm{C}+$ VLDL-cholesterol and TAG with no effect on HDL-C. As reported by Munday et al. ${ }^{49}$, dietary CLA did not produce significant differences in serum TC or HDL-C in mice. At the same time, the mice fed CLA showed significantly higher HDL-C : TC ratio and significantly lower TAG concentrations compared to control animals. In contrast to the present findings, increasing dietary CLA in rabbits $(0.0-1.0 \%)$ led to higher serum TC and TAG levels ${ }^{9}$. Interestingly, the above effects were attenuated at lower dietary CLA concentrations ${ }^{10}$. In studies involving healthy human subjects ${ }^{11}$, isomeric blends of CLA isomers (cis-9, trans-11:trans-10, cis-12; $50: 50$ and $80: 20)$ were used. The 50:50 CLA isomer blend reduced plasma TAG concentrations whereas the 80:20 CLA isomer blend reduced VLDL-cholesterol concentrations. More recently, isomer-specific effects of CLA were studied in detail. It was shown, that cis-9, trans-11 CLA increased plasma HDL-C as well as HDL-C : LDL-C ratio ${ }^{13}$. Opposing effects of cis-9, trans-11 and trans-10, cis-12 CLA were also reported by Tricon et al. ${ }^{12}$. Namely the former isomer decreased favourably the LDL-C: HDL-C ratio and the TC: HDL-C ratio in healthy human subjects, whereas the latter increased them.

A single attempt to verify potential anti-atherogenic properties of eggs (egg yolks) naturally enriched with CLA was also made ${ }^{24}$. The rats fed these eggs (egg yolks) showed favourable changes in plasma lipids: plasma TC and LDL-C were decreased, whereas concentrations of HDL-C were increased. No changes in serum TAG concentrations were observed and liver cholesterol was sharply decreased $(\sim 50 \%)$ in rats fed the CLA-enriched egg yolks.

Very recently, hypocholesterolaemic effects of CLA-enriched butter on hamsters were studied ${ }^{50,51}$. In both experiments, CLAenriched butter altered plasma lipoprotein profiles (lower TC and LDL-C, higher HDL-C) that could be associated with a reduced risk of atherosclerosis. No such effects were noted in human subjects who were offered dairy products with naturally incorporated CLA ${ }^{52,53}$

Several mechanisms have been proposed to explain the effects of CLA isomers on plasma lipid profiles in laboratory animals and man. It was postulated that CLA may reduce the number of LDL particles by inhibition of hepatic synthesis of apoB-containing lipoproteins ${ }^{54}$. CLA may also increase the LDL receptor activity and thus increase the clearance rate of LDL in blood circulation ${ }^{55}$. According to Yeung et $a l .{ }^{56}$, CLA down-regulates intestinal acyl CoA: cholesterol acyltranferase activity, increases the excretion of sterols and consequently decreases serum cholesterol concentration in hamsters.
With the advent of nutritional genomics, novel mechanisms by which dietary CLA might modulate plasma lipids have been suggested ${ }^{57}$. CLA are considered to be ligands of nuclear transcription factors, i.e. PPAR- $\alpha$ and sterol regulatory element binding protein-1, which are involved in lipid hepatic metabolism. For instance, activation of PPAR- $\alpha$ by CLA may lead to several effects, e.g. reduction of fatty acid and TAG synthesis and VLDL production. Sterol regulatory element binding protein-1 is a regulator of genes encoding enzymes involved in both lipogenesis and cholesterol biosynthesis, thus providing a mechanism by which CLA may decrease plasma cholesterol and TAG levels.

The third type of biological marker chosen in the present experiment was development of pre-established atherosclerosis and composition of atherosclerotic plaque in apoE/ $\mathrm{LDLR}^{-1-}$ mice. ApoE/LDLR ${ }^{-1-}$ mice represent a unique and reliable model of atherogenesis that allows quantification of anti-atherogenic activities of pharmacological tools ${ }^{25-27}$. Using this model, we assessed the functional (anti-atherogenic) effects of CLA-enriched eggs. We found that treatment of apoE/LDLR ${ }^{-1-}$ mice with CLA-enriched or CLA-supplemented eggs tended to, but did not consistently, diminish the area of atherosclerotic plaque. This may be due to shorter treatment time (2 months) as compared to our previous studies (4 months) $)^{25-27}$ as well as the starting point of the treatment in mice, at the age of 4 months, at which apoE/LDLR ${ }^{-1-}$ mice have already established atherosclerosis. Quite surprisingly, we found that CLA-enriched eggs, but not CLA-supplemented eggs, considerably attenuated inflammatory vascular response, by reducing the number of macrophages in atherosclerotic plaques. At the same time, CLA-supplemented eggs increased the abundance of smooth muscle cells in these plaques. It is well known that the intensity of vascular inflammatory response in atherosclerosis depends on the abundance and activation of macrophages as well as other inflammatory cells and is inversely associated with low abundance of homogenous area covered by smooth muscle cells ${ }^{33}$. Thus, the present results support the conclusion that CLA-enriched eggs limited vascular inflammatory response. Consequently, CLA-enriched eggs exerted the antiinflammatory and anti-atherogenic effect more effectively than CLA-supplemented eggs, at the same level of dietary intake $(0.1 \%)$. This striking difference in anti-atherogenic effects of the CLA-supplemented and CLA-enriched diets may perhaps be explained by different proportions of cis-9, trans-11 and trans-10, cis-12 CLA isomers in the CLA-supplemented eggs (50:50) and CLA-enriched eggs (80:20). Moreover, the present findings would strongly support the notion of the opposing effects of cis-9, trans-11 and trans10 , cis-12 CLA isomers in $\operatorname{man}^{12}$. It was shown recently ${ }^{15}$ that feeding an $80: 20$ isomeric blend of cis-9, trans-11 and trans-10, cis-12 CLA isomers, at a high dietary concentration of $1.0 \%$, to apoE-deficient mice with pre-established atherosclerosis resulted in its profound resolution. It was accompanied by reduced expression of CD68 within the aortic lesions and down-regulation of the expression of proinflammatory genes.

The above effects could be potentially associated with incorporation of CLA isomers into atherosclerotic plaques. Indeed, it has been shown already that dietary $n-3$ PUFA (derived from fish oils) were readily incorporated into athero- 
sclerotic plaques of men, reduced macrophage numbers within the plaques and thus the probability of rupture ${ }^{58}$. Very recently, Ringseis et al. ${ }^{59}$ clearly demonstrated that both cis9, trans-11 and trans-10, cis-12 CLA isomers were incorporated and metabolized in human vascular endothelial cells to biologically active compounds, mediating the anti-inflammatory and anti-atherogenic actions of CLA.

In conclusion, the above evaluation of functional properties of eggs (egg yolks) naturally enriched with CLA isomers (cis-9, trans-11 and trans-10, cis-12) supports generally our hypothesis that CLA-enriched eggs can be considered a functional food. These products: preserve conventional characteristics of hen eggs; can be consumed in conventional human diets; and contain the CLA isomers that are natural and active components of ruminant fat. Moreover, the evaluation of health-related effects of CLA-enriched eggs indicated that CLA-enriched eggs reduced significantly $(P<0.05)$ total plasma cholesterol in the atherosclerotic mice. Also, CLAsupplemented and CLA-enriched eggs tended to lower the severity of atherosclerosis as evaluated in aortic roots. Furthermore, the mice fed CLA-enriched eggs showed significantly $(P<0.05)$ reduced expression of atherogenic macrophages in aortic plaques and increased expression of SMA in aortic plaques of these mice (in aortic roots). Consequently, CLAenriched eggs could have exerted the anti-inflammatory and anti-atherogenic effect more effectively than CLA-supplemented eggs, at the same level of dietary intake $(0 \cdot 1 \%)$. This effect can be considered a major functional claim of CLA-enriched eggs. To date, there have been no studies on whether CLA, fed as an integral component of eggs, has functional (i.e. anti-atherogenic) properties, similar to those of CLA isomers fed as NEFA. Interestingly, the urgent need for studies using direct measures of arterial plaques, in order to assess how nutritional intervention can influence the development of atherosclerosis, has been recently expressed ${ }^{60}$.

\section{References}

1. Griinari JM \& Bauman DE (1999) Biosynthesis of conjugated linoleic acid and its incorporation into meat and milk in ruminants. In Advances in Conjugated Linoleic Acid Research, pp. 180-199 [MP Yurawecz, MM Mossoba, JKG Kramer, MW Pariza and GJ Nelson, editors]. Champaign, IL: AOCS Press.

2. Evans M, Brown J \& McIntosh M (2002) Isomer-specific effects of conjugated linoleic acid (CLA) on adiposity and lipid metabolism. J Nutr Biochem 13, 508-516.

3. Terpstra AH, Javadi M, Beynen AC, Kocsis S, Lankhorst AE, Lemmens AG \& Mohede IC (2003) Dietary conjugated linoleic acids as free fatty acids and triacylglycerols similarly affect body composition and energy balance in mice. $J$ Nutr 133, 3181-3186.

4. Wang Y \& Jones PJH (2004) The role of conjugated linoleic acid in human health. Dietary conjugated linoleic acid and body composition. Am J Clin Nutr 79, 1153S-1158S.

5. Gaullier JM, Halse J, Hoye K, Kristiansen K, Fagertun H, Vik H \& Gudmundsen O (2005) Supplementation with conjugated linoleic acid for 24 months is well tolerated by and reduces body fat mass in healthy, overweight humans. $J$ Nutr 135, 778-784.

6. Belury MA (2002) Inhibition of carcinogenesis by conjugated linoleic acid: potential mechanisms of action. J Nutr 132, 2995-2998

7. Field CJ \& Schley PD (2004) Evidence for potential mechanisms for the effect of conjugated linoleic acid on tumor metab- olism and immune function: lessons from n-3 fatty acids. Am $J$ Clin Nutr 79, 1190S-1198S.

8. Cho HJ, Kim EJ, Lim SS, Kim MK, Sung MK, Kim JS \& Park JHY (2006) Trans-10,cis-12, not cis-9, trans-11, conjugated linoleic acid inhibits G1-S progression in HT-29 human colon cancer cells. J Nutr 136, 893-898.

9. Kritchevsky D, Tepper SA, Wright S, Tso P \& Czarnecki SK (2000) Influence of conjugated linoleic acid (CLA) on establishment and progression of atherosclerosis in rabbits. $J$ Am Coll Nutr 19, 472S-477S

10. Kritchevsky D, Tepper SA, Wright S \& Czarnecki SK (2002) Influence of graded levels of conjugated linoleic acid (CLA) on experimental atherosclerosis in rabbits. Nutr Res 22, $1275-1279$.

11. Noone EJ, Roche HM, Nugent AP \& Gibney MJ (2002) The effect of dietary supplementation using isomeric blends of conjugated linoleic acid on lipid metabolism in healthy human subjects. Br J Nutr 88, 243-251.

12. Tricon S, Burdge GC, Kew S, et al. (2004) Opposing effects of cis-9,trans-11 and trans-10,cis-12 conjugated linoleic acid on blood lipids in healthy humans. Am J Clin Nutr 80, 614-620.

13. Valeille K, Gripois D, Blouquit MF, Souidi M, Riottot M, Bouthegourd JC, Serougne C \& Martin JC (2004) Lipid atherogenic risk markers can be more favourably influenced by the cis-9 trans-11-octadecadienoate isomer than a conjugated linoleic acid mixture or fish oil in hamsters. Br J Nutr 91, 191-199.

14. Arbonés-Mainar JM, Navarro MA, Acín S, Guzmán MA, Arnal C, Surra JC, Carnicer R, Roche HM \& Osada J (2006) Trans-10, cis-12- and cis-9, trans-11-Conjugated linoleic acid isomers selectively modify HDL-apolipoprotein composition in apolipoprotein E knockout mice. J Nutr 136, 353-359.

15. Toomey S, Harhen B, Roche HM, Fitzgerald D \& Belton O (2006) Profound resolution of early atherosclerosis with conjugated linoleic acid. Atherosclerosis 187, 40-49.

16. O'Shea M, Bassaganya-Riera J \& Mohede ICM (2004) Immunomodulatory properties of conjugated linoleic acid. $A m J$ Clin Nutr 79, 1199S-1206S.

17. Tricon S, Burdge GC, Kew S, Banerjee T, Russell JJ, Grimble RF, Williams ChM, Calder PC \& Yaqoob P (2004) Effects of cis-9, trans-11 and trans-10, cis-12 conjugated linoleic acid on immune cell function in healthy humans. Am J Clin Nutr 80, 1626-1633.

18. Aggett PJ, Antoine JM, Asp NG, et al. (2005) PASSCLAIM process for the assessment of scientific support for claims on foods, Consensus on Criteria. Eur J Nutr 44, 1S-30S.

19. Azain MJ (2003) Conjugated linoleic acid and its effects on animal products and health in single stomached animals. Proc Nutr Soc 62, 319-328.

20. Raes K, De Smet S \& Demeyer D (2004) Effects of dietary fatty acids on incorporation of long chain polyunsaturated fatty acids and conjugated linoleic acid in lamb, beef and pork meat. Anim Feed Sci Tech 113, 199-221.

21. Givens DI (2005) The role of animal nutrition in improving the nutritive value of animal-derived foods in relation to chronic disease. Proc Nutr Soc 64, 395-402.

22. Pisulewski PM, Franczyk M \& Kostogrys RB (2005) Heathrelated effects of nutritionally modified foods of animal origin. J Anim Feed Sci 14, 71S-85S.

23. Schmid A, Collomb M, Sieber R \& Bee G (2006) Conjugated linoleic acid in meat and meat products: a review. Meat Sci 73, 29-41.

24. Szymczyk B \& Pisulewski P (2002) Feeding conjugated linoleic acid-enriched egg yolks alters serum lipid profile in adult rats. Ann Anim Sci 2, 171-178.

25. Jawien J, Gajda M, Rudling M, Mateuszuk L, Olszanecki R, Guzik TJ, Cichocki T, Chlopicki S \& Korbut R (2006) Inhibition of five lipoxygenase activating protein (FLAP) by MK-886 decreases atherosclerosis in apoE/LDLR-double knockout mice. Eur J Clin Invest 36, 141-146. 
26. Olszanecki R, Jawien J, Gajda M, Mateuszuk L, Gebska A, Korabiowska M, Chlopicki S \& Korbut R (2005) Effect of curcumin on atherosclerosis in apoE/LDLR-double knockout mice. $J$ Physiol Pharmacol 56, 627-635.

27. Jawien J, Csanyi G, Gajda M, Mateuszuk L, Lomnicka M, Korbut R \& Chlopicki S (2007) Ticlopidine attenuates progression of atherosclerosis in apolipoprotein $\mathrm{E}$ and low density lipoprotein receptor double knockout mice. Eur J Pharmacol 556, 129-135.

28. Szymczyk B \& Pisulewski PM (2003) Effects of dietary conjugated linoleic acid on fatty acid composition and cholesterol content of hen egg yolks. Br J Nutr 90, 93-99.

29. Franczyk-Żarów M (2006) Assessment of atherosclerotic plaque in genetically modified mice (ApoE/LDLR ${ }^{-1-}$ ) feeding CLAenriched egg yolks PhD Thesis (in Polish)

30. Ishibashi S, Herz J, Maeda N, Goldstein JL \& Brown MS (1994) The two-receptor model of lipoprotein clearance: tests of the hypothesis in 'knockout' mice lacking the low density lipoprotein receptor, apolipoprotein E, or both proteins. Proc Natl Acad Sci U S A 91, 4431-4435.

31. Reeves PG, Nielsen FH \& Fahey GC (1993) AIN-93 purified diets for laboratory rodents: final report of the American Institute of Nutrition ad hoc Writing Committee on the reformulation of the AIN-76A rodent diet. J Nutr 123, 1939-1951.

32. Nicoletti A, Kaveri S, Caligiuri G, Bariety J \& Hansson GK (1998) Immunoglobulin treatment reduces atherosclerosis in apo E knockout mice. J Clin Invest 102, 910-918.

33. Elhage R, Jawien J, Rudling M, Ljunggren HG, Takeda KS, Akira S, Bayard F \& Hansson GK (2003) Reduced atherosclerosis in interleukin-18 deficient apolipoprotein E - knockout mice. Cardiovasc Res 59, 234-240.

34. Robertson AK, Rudling M, Zhou X, Gorelik L, Flavell RA \& Hansson GK (2003) Disruption of TGF-beta signaling in T cells accelerates atherosclerosis. J Clin Invest 112, 1342-1350.

35. Bellisle F, Diplock AT, Hornstra G, Koletzko B, Roberfroid M, Salminen S \& Saris WHM (1998) Functional food science in Europe. Br J Nutr 80, 1S-193S.

36. Roberfroid MB (2002) Global view on functional foods: European perspectives. Br J Nutr 88, S133-S138.

37. Schäfer K, Männer K, Sagredos A, Eder K \& Simon O (2001) Incorporation of dietary linoleic acid and conjugated linoleic acids and related effects on eggs of laying hens. Lipids 36, 1217-1222.

38. Raes K, Heyghebaert G, De Smet S, Nollet L, Arnouts S \& Demeyer D (2002) The deposition of conjugated linoleic acid in eggs of laying hens fed diets varying in fat level and fatty acid profile. J Nutr 132, 182-189.

39. Shang XG, Wang FL, Li DF, Yin JD \& Li JY (2004) Effects of dietary conjugated linoleic acid on the productivity of laying hens and egg quality during refrigerated storage. Poult Sci $\mathbf{8 3}$, $1688-1695$.

40. Cachaldora P, Garcia-Rebollar P, Alvarez C, Mendel J \& de Blas JC (2005) Effect of conjugated linoleic acid, high-oleic sunflower oil and fish oil dietary supplementation on laying hen egg quality. Spanish J Agric Res 3, 74-82.

41. Hasler CM (2000) The changing face of functional foods. $J$ Am Coll Nutr 19, 499S-506S.

42. Surai PF \& Sparks NHC (2001) Designer eggs: from improvement of egg composition to functional food. Trends Food Sci Technol 12, 7-16.

43. Kramer JK, Cruz-Hernandez C, Deng Z, Zhou J, Jahreis G \& Dugan ME (2004) Analysis of conjugated linoleic acid and trans 18:1 isomers in synthetic and animal products. Am $J$ Clin Nutr 79, 1137S-1145S.
44. Belury MA, Mahon A \& Banni S (2003) The conjugated linoleic acid (CLA) isomer, t10c12-CLA, is inversely associated with changes in body weight and serum leptin in subjects with type 2 diabetes mellitus. $J$ Nutr 133, 257S-260S.

45. Burdge GC, Lupoli B, Russell JJ, et al. (2004) Incorporation of cis9,trans-11 or trans-10,cis-12 conjugated linoleic acid into plasma and cellular lipids in healthy men. J Lipid Res 45, 736-741.

46. Payet M, Esmail MH, Polichetti E, le Brun G, Adjemout L, Donnarel G, Portugal H \& Pieroni G (2004) Docosahexaenoic acid-enriched egg consumption induces accretion of arachidonic acid in erythrocytes of elderly patients. $B r J$ Nutr 91, 789-796.

47. Lee KN, Kritchevsky D \& Pariza MW (1994) Conjugated linoleic acid and atherosclerosis in rabbits. Atherosclerosis 108, $19-25$.

48. Nicolosi RJ, Rogers EJ, Kritchevsky D, Scimeca JA \& Huth PJ (1997) Dietary conjugated linoleic acid reduces plasma lipoproteins and early atherosclerosis in hypercholesterolemic hamsters. Artery 22, 266-277.

49. Munday JS, Thompson KG \& James KAC (1999) Dietary conjugated linoleic acids promote fatty streak formation in the C57BL/6 mouse atherosclerosis model. Br J Nutr 81, 251-255.

50. Lock AL, Horne CA, Bauman DE \& Salter AM (2005) Butter naturally enriched in conjugated linoleic acid and vaccenic acid alters tissue fatty acids and improves the plasma lipoprotein profile in cholesterol-fed hamsters. J Nutr 135, 1934-1939.

51. Valeille K, Ferezou J, Parquet M, Amsler G, Gripois D, Quignard-Boulange A \& Martin JC (2006) The natural concentration of the conjugated linoleic acid, cis-9,trans-11, in milk fat has antiatherogenic effects in hyperlipidemic hamsters. $J$ Nutr 136, 1305-1310.

52. Desroches S, Chouinard PY, Galibois I, Corneau L, Delisle J, Lamarche B, Couture P \& Bergeron N (2005) Lack of effect of dietary conjugated linoleic acids naturally incorporated into butter on the lipid profile and body composition of overweight and obese men. Am J Clin Nutr 82, 309-319.

53. Tricon S, Burdge GC, Jones EL, et al. (2006) Effects of dairy products naturally enriched with cis- 9 , trans- 11 conjugated linoleic acid on the blood lipid profile in healthy middle-aged men. Am J Clin Nutr 83, 744-753.

54. Yotosumoto H, Hara E \& Naka S (1999) 10 trans, 12 cis linoleic acid reduces apolipoprotein B secretion in HepG2 cells. Food Res Int 31, 403-409.

55. Grundy SM \& Denke MA (1990) Dietary influences on serum lipids and lipoproteins. J Lipid Res 31, 1149-1172.

56. Yeung ChH, Yang L \& Huang Y (2000) Dietary conjugated linoleic acid mixture affects the activity of intestinal acyl coenzyme A: cholesterol acyltransferase in hamsters. Br J Nutr 84, 935-941.

57. Fernandez ML \& West KL (2005) Mechanisms by which dietary fatty acids modulate plasma lipids. J Nutr 135, 2075-2078.

58. Thies F, Garry JMC, Yaqoob P, Rerkasem K, Williams J, Shearman CP, Gallager PJ, Calder PC \& Grimble RF (2003) Association of n3 polyunsaturated fatty acids with stability of atherosclerotic plaques: a randomized controlled trial. Lancet 361, 477-485.

59. Ringseis R, Muller A, Dusterloh K, Schleser S, Eder K \& Steinhart H (2006) Formation of conjugated linoleic acid metabolites in human vascular endothelial cells. Biochim Biophys Acta 1761, 377-383.

60. Hamer M \& Steptoe A (2006) Influence of specific nutrients on progression of atherosclerosis, vascular function, haemostasis and inflammation in coronary heart disease patients: a systematic review. Br J Nutr 95, 849-859. 